physicians who advertise their prices and compete for patients, but would allow the American Medical Association to set guidelines to prevent false and misleading claims.

\section{Department of Education}

The first secretary of the newly created U.S. Department of Education

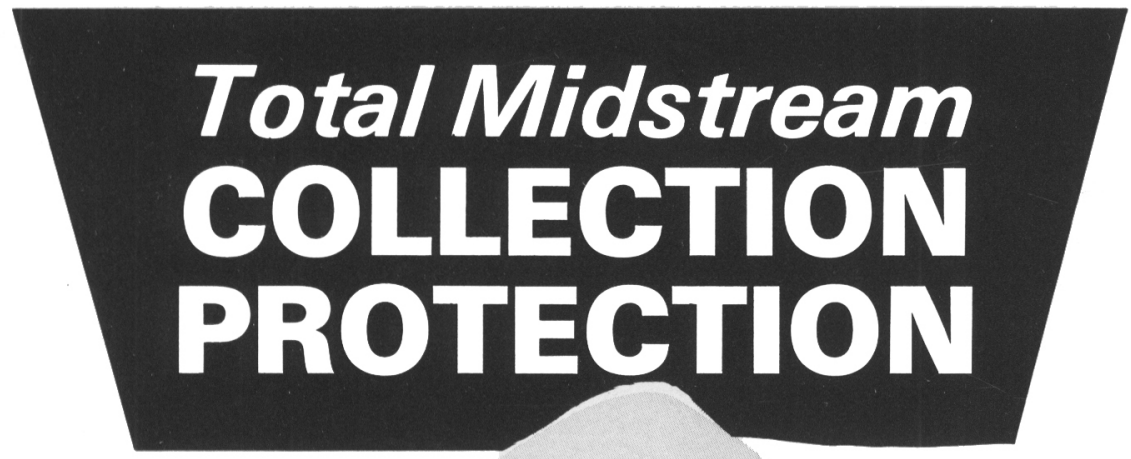

- packaged in order of use

- provides better technique for collecting contamination-free specimen

- choice of lodophor or Castile soap towelettes

Sage Midstream Urine Collection Kit is packaged in order of use in sterile airtight blister package. Kit is designed to protect specimens against external organisms and patient handling before, during and after voiding. is Shirley M. Hufstedler, a judge on the ninth U.S. circuit court of appeals in California and a strong proponent of civil liberties. The new Department, created out of the Department of Health, Education, and Welfare, will have only limited jurisdiction; state and local governments will still control education policy.

\section{Health Maintenance Organizations}

HMOs are gaining increased interest from Capitol Hill. Most prepaid health plans were exempted from the new planning law; appropriations for fiscal 1980 are almost double those of 1979; a series of bills measures other insurance plans against HMOs; HMOs are prominent in most national health insurance proposals. HEW's 10-year strategy is to increase nationwide HMO membership from the current 7.5 billion enrollees to 19 million.

The House Ways and Means Committee has adopted the HEW proposal that HMOs be reimbursed at $95 \%$ of the fee-for-service rates allowed by Medicare. Traditionally, HMOs cost the government about 20\% less; this "bonus" payment would provide additional benefits for elderly HMO members. The full House is expected to approve this proposal, but Senate acceptance without major revisions is considered unlikely.
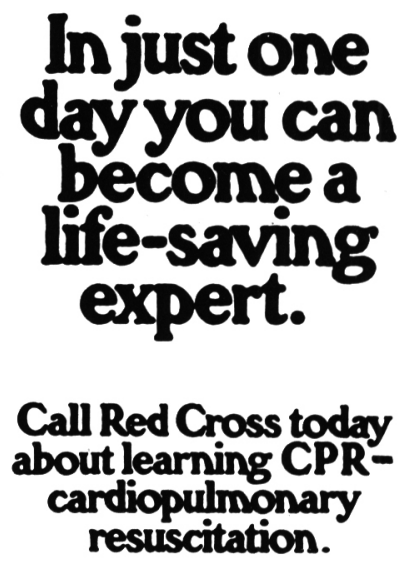

Cap well eliminates need for separate packaging of cap.

Key to proper patient use and reduced retakes:

1. See-through packaging for quick identification with instructions and order of use of components.

2. Instructions for use of kit clearly explained and packaged on top.

3. Three individually packaged towelettes in choice of lodophor or Castile soap for pre-delivery preparation.

4. Funnel and container is a simple, twist-off assembly.

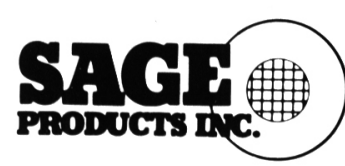

For free sample and further information, call or write Sage Products, Inc., 1300 Morse Ave., Elk Grove Village, Illinois 60007; 312/593-2140. 